\title{
Convective Heat Transfer in Impinging- Gas- Jet Arrangements
}

\author{
J. M. Buchlin ${ }^{\dagger}$ \\ von Karman Institute for Fluid Dynamics, Chaussée de Waterloo 72, Rhode-Saint- Genèse, B- 1640, Belgium \\ †Corresponding Author Email: buchlin@vki.ac.be
}

(Received July 16, 2010; accepted March 13, 2011)

\begin{abstract}
The paper deals with heat transfer by convection between impinging gas jets and solid surfaces. It considers both single and multiple jet systems. It emphasizes the flow and geometrical parameters as well as the environment conditions at which the jet emerges. In particular, it points out the effect of the jet tilting, thermal entrainment and jet confinement. ASN and ARN schemes are illustrated through industrial and aeronautical applications. Design correlations are proposed. Experimental data obtained from infrared thermography are compared to CFD simulations.
\end{abstract}

Keywords: Convective impinging, Cooling \& heating, IR Thermography, CFD simulation.

\section{NOMENCLATURE}

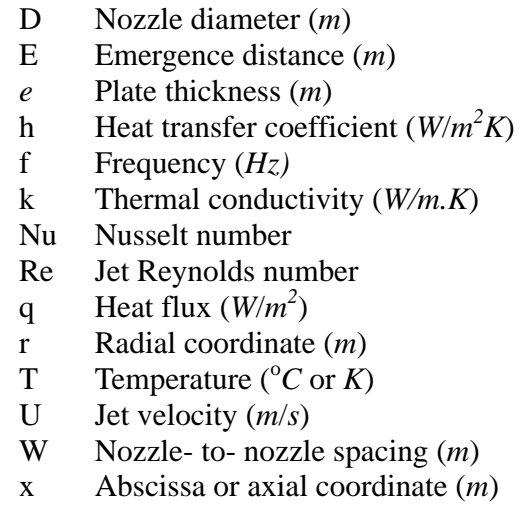

\section{INTRODUCTION}

The conversion and control of energy requires improving and mastering heat exchange mechanisms, which finally determine the efficiency of all the energetic systems.

Among heat transfer devices, impinging fluid jets are extensively exploited because of their ability to produce high local transport coefficients. Indeed, the large heat transfer rate obtained with impinging streams, compared with classical boundary layer flows explain the popularity of this technique. In addition, impingement is often attractive for the designer, who can easily control the area and the distribution of thermal exchange. Impinging jet systems are present in many industrial and engineering processes where heat and/or mass transfer prevail. Typical examples are the annealing of metal and plastic belts, the tempering of glass sheets, the drying of paper and textiles, the

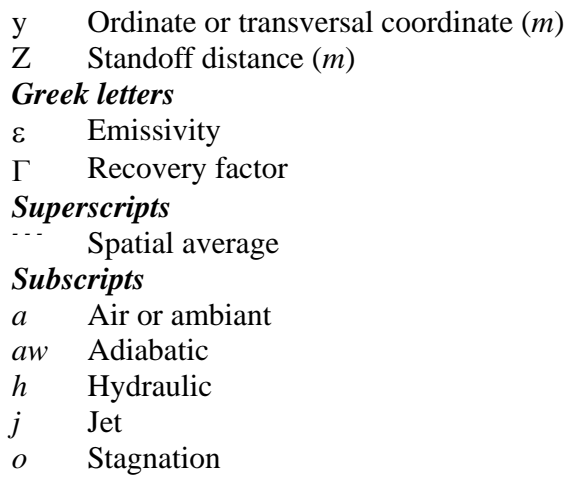

cooling of turbine blades, the chemical vapour deposition, propulsion jet- to- flaps interaction in STOL aircraft and the aircraft antiicing.

The jet can be formed by round (SRN) or slot nozzle (SSN) depending on the application. In some situations, the jet expands in a confined space either because the standoff distance of the nozzle exit with respect to the solid surface is small or because roofing exists around the jet or because the jet is surrounded by other neighbouring jets. If the impacted surface is concave the jet may flaps naturally. Moreover, most of the heat transfer systems rely on arrays of nozzles often characterised by small pitch ratio. All these circumstances may affect the jet development and modify the impingement conditions so that the heat transfer differs from the classical unconfined single jet conditions.

In this perspective, the paper discusses the thermal convective exchange between impinging 
incompressible gas jets and solid surfaces. The single and multiple jet systems are successively considered. The flow and geometrical parameters and the environment conditions at which the jet emerges are emphasised. In particular, the effect of the jet tilting, thermal entrainment and jet confinement are pointed out. Array of slot nozzles (ASN) and array of round nozzles (ARN) schemes are illustrated through industrial and aeronautical applications. Design correlations are proposed. Experimental data obtained from infrared thermography are compared to CFD simulations.

\section{EXPERIMENTAL METHODOLOGY}

Different methods have been proposed to determine the local and average convective heat transfer on surface impacted by fluid jets. Most of them are experimental. They generally rely on the use of heated or cooled flat plate instrumented with temperature sensors and/or calorimeters (Huang 1963; Hollworth \& Berry 1978; Hrycak 1983; Goldstein \& Behbahani 1982; Hollworth \& Wilson 1984; Hollworth and Gero 1985; Goldstein et al. 1986, 1990). However, mass transfer analogy involving water evaporation (Martin 1977), naphthalene sublimation (Koopman \& Sparrow 1976; Sparrow \& Lovell 1980) or diffusion- controlled electrolysis (Vallis et al. 1978) is also adopted.

Nowadays, electro- optical techniques with (quasi) nonintrusive property such as liquid crystal method and infrared thermography have emerged. They yield both flow visualization and quantitative measurements when associated with digital image processing (Buchlin 1986 a- b; Buchlin \& Arts 1991; Balageas 1993; Carlomagno 1993, 1997; and Carlomagno et al. 1998). Liquid crystal technique has been successfully applied to heat transfer of single jet and arrays of jets (Den Ouden \& Hoogendoorn 1974; Goldstein \& Timmers 1982; Baughn \& Shimizu 1989). The author has initiated the application of quantitative thermography to thermal diagnostic of jet impingement onto a thin heated foil (Buchlin 1986a; Gartenberg 1992). Further studies have proved that such a technique is a convincing tool for temperature measurements of high resolution at the impact zone of an impinging jet (De Luca et al. 1992; Page et al. 1993; and Meola et al. 1994, 1995, 1996). The potency of the quantitative infrared thermography to determine accurately the convective heat transfer coefficients in many flow situations has been extensively demonstrated (Buchlin 1993; Buchlin \& Tasse 1996; Buchlin \& Pelmann 1996; Carlomagno 1997; Carlomagno et al. 1998; Buchlin \& Chartier 1999; Buchlin 2002; Buchlin 2010).

Finally, it is worth noting that Martin (1977) and Jumbunathan et al. (1992) have presented extended reviews of heat transfer data of impinging, where design correlations for several nozzle types and nozzle arrangements can be appraised.

Figure 1 outlines a typical arrangement of the experimental IR Thermography set- up commonly operating at the VKI for SRN, SSN, ARN and ASN investigations. For SRN, simple pipe or aerodynamic convergent nozzle may produce the round air; the exit diameter $\mathrm{D}$ is ranged from $0.005 \mathrm{~m}$ to $0.05 \mathrm{~m}$. For SSN, the slot size may vary from $0.001 \mathrm{~m}$ to $0.08 \mathrm{~m}$.

A heat exchanger controls the air temperature of the resulting jet(s). The impacted target consists of a horizontal flat or concave plate made of a thin copper foil, $40 \mu \mathrm{m}$ thick, fixed on an epoxy sheet with thickness less than $1 \mathrm{~mm}$. The foil is chemically treated or machined to produce tight groves of about 1 or $2 \mathrm{~mm}$ forming a continuous electrical resistance of high value. The resulting circuit is connected to an electrical generator monitored by ammeter and voltmeter. The foil is uniformly heated by Joule effect.

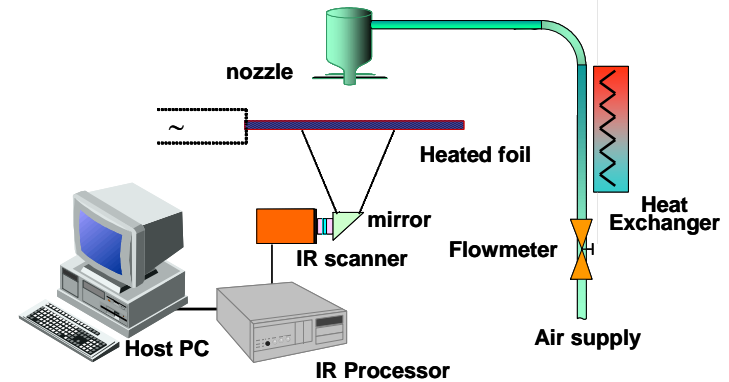

Fig. 1. Principle of IRTh test setups

The rear face of target is scanned by the IR camera; it is coated with a black paint of emissivity $\varepsilon_{\mathrm{w}}=0.96$ to improve the IR thermography measurements and allow correction for radiation. It is worth noting that the thermo foil Biot number, $\mathrm{Bi}=\mathrm{h} . \mathrm{e} / \mathrm{k}$, is generally small enough $(<0.1)$ to neglect temperature variation through the plate. Nevertheless, the plate encompasses flush mounted thermocouples that allow the fine calibration of the IR measurements.

The local convective heat transfer coefficient is inferred from the steady- state temperature of the local wall $T_{w}$ by application of the Newton law:

$h=\frac{q_{c v}}{T_{w}-T_{\text {ref }}}$

$\mathrm{T}_{\text {ref }}$ is a reference jet temperature; it could be the recovery temperature $T_{a w}$ or the plenum temperature $T_{j}$. The choice of $\mathrm{T}_{\text {ref }}$ depends on the exit jet conditions such as the jet Mach number (compressibility effect), the mismatch temperature between the jet and the surounding environment, ( $\$ 3.1 .4)$

The convective flux $\mathrm{q}_{\mathrm{cv}}$ is determined by subtracting the heat losses, $\mathrm{q}_{\mathrm{l}}$, to the Joule heating, $\mathrm{q}_{\mathrm{J}}$. The heat losses include the contribution of the radiation, $\mathrm{q}_{\mathrm{rad}}$, of the conduction, $\mathrm{q}_{\mathrm{cd}}$, and of a possible natural convection on the face not exposed to the jet flow. The twodimensional fin theory allows the derivation of the following expression:

$\mathrm{q}_{\ell}=-\mathrm{e} \nabla\left(\mathrm{k} \nabla \mathrm{T}_{\mathrm{w}}\right)+\mathrm{h}_{\text {tot }}\left(\mathrm{T}_{\mathrm{w}}-\mathrm{T}_{\mathrm{a}}\right)$

The global heat transfer coefficient, $\mathrm{h}_{\text {tot }}$, models both natural convection and thermal radiation effects. Eqs. (1) and (2) show that the convective heat transfer coefficient is determined readily once the foil properties and the temperature field $\mathrm{T}_{\mathrm{w}}$ are known. 
The evaluation of the conduction term is trickier: it requires an estimation of the second derivative of the wall- temperature distribution. Such a computation, which may introduces significant noise, demands to smooth properly the IR raw data before final processing. In steady state experiments as it it is the case here, the noise reduction can be achieved by averaging a sufficient number of thermogrammes (thermal images) acquired in a time sequence. Another procedure consist applying a filtering algorithm. For instance, a fast Fourier transform of the signal and appropriate restoration of the thermogramme allow the elimination of spurious high frequency oscillations in the temperature field.

The aforeproposed thin- foil design, where the grooves are perpendicular to the heat flow direction both for the round and slot jets leads to minimise the conduction loss, which typically does not exceed $2 \%$ of the convective flux. The heat loss by radiation remains generally smaller than $5 \%$ of the total flux. Detailed error analysis indicates that the local uncertainty of the convective $\mathrm{h}$ - value is around $10 \%$.

\section{RESUlTS}

\subsection{SRN Jet}

\subsubsection{Isothermal Round Jet}

Experiments have been conducted with isothermal (temperature equal to ambiant temperature) round jet impinging perpendicularly to a flat plate. Figure 2 shows a typical IR thermogramme (false colors). It demonstrates the good axisymmetry of the thermal field. The non- uniform temperature field exhibits concentric cold and hot rings revealing the presence of high and low heat transfer regions.

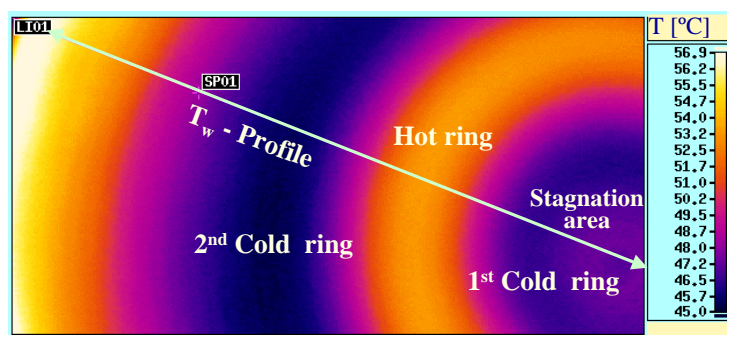

Fig. 2.Temperature mapping at the impingement of a perpendicular SRN jet.

Such a thermal distribution agrees perfectly with velocity field obtained by PIV measurements as presented in Fig. 3 (Buchlin \& Laperches 1998).

The arrows in Fig. 3 draw attention on the main observations, which agree in every respect with the sparse literature on the subject (Landreth et al. 1990; Meola et al. 1996). A radial acceleration zone is detected just after the stagnation point in a region located between 0.6 and $1 \mathrm{r} / \mathrm{D}$. Then a wall jet builds up counter rotating primary and secondary vortex rings (the latter not very well captured due to light reflection problem): that provokes local flow detachment causing heat transfer decrease, and then flow reattachment located at about $r / \mathrm{D}=2.4$ (with a good repeatability) where transition to turbulence of the wall jet is anticipated and subsequent heat transfer rise is detected.

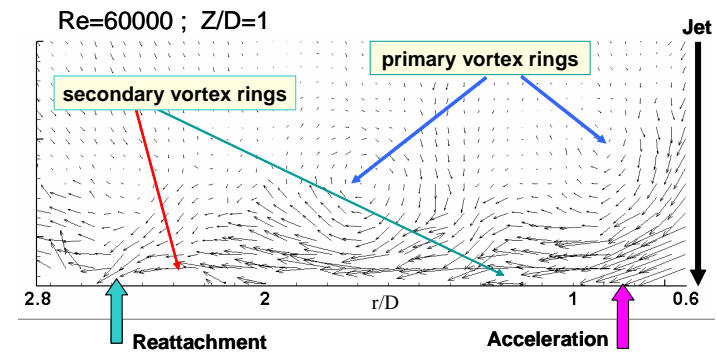

Fig. 3. Velocity vector mapping from PIV at the impingement of perpendicular SRN jet

The radial distribution (along line drawn in Fig. 2) of the local Nusselt number, $\mathrm{Nu}=\mathrm{hD} / \mathrm{k}_{\mathrm{a}}$, is plotted in Fig. 4. The effect of the jet Reynolds number Re and the normalised standoff distance Z/D on the radial Nusselt number distribution is emphasized.

At very small standoff distance the $\mathrm{Nu}$ - profile displays two distinct peaks. The inner (primary) maximum happens around $\mathrm{r} / \mathrm{D}=0.7$ while the outer (secondary) peak is situated close to $r / D=2.4$. These two heat transfer peaks correlate very well with the acceleration and the reattachment and/or turbulent zones of the wall jet as depicted in Fig. 3. At small discharge distance, the secondary peak dominates as Re increases. As higher standoff distance and/or as the Reynolds number decreases the inner and outer peaks vanish and the maximum heat transfer moves to the stagnation point; there, the distribution takes a conventional bell shape profile. All these heat transfer distributions corroborate very well with other findings published in the literature (Gardon \& Akfirat 1965; Den Ouden \& Hoogendoorn 1974; Baughn \& Shimizu 1989; and Meola et al. 1994).

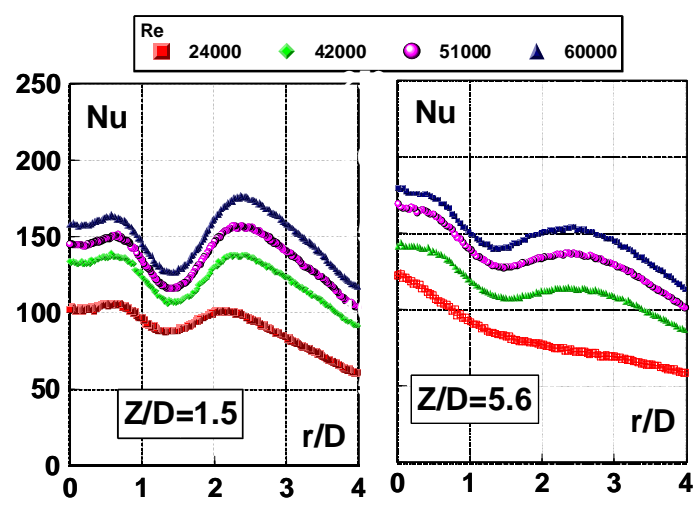

Fig. 4. Radial Nu- profile for perpendicular SRN jet. Effect of Reynolds number and standoff distance

The magnitude and position of the two heat transfer peaks are plotted in function of the standoff distance in Fig. 5. The primary peak remains located at $r / D=0.7$ where flow acceleration develops. The position of the secondary peak, which is linked to the flow reattachment and/or turbulence occurrence, evolves: it moves outwards as Z/D increases and stops at about $\mathrm{r} / \mathrm{D}=2.4$ when $\mathrm{Z} / \mathrm{D}$ becomes larger than 2. Such 
behaviour agrees well with the Lytle \& Web data (1991). Below $\mathrm{Z} / \mathrm{D}=2$ the outer peak is the stronger, especially when Re is large; above $\mathrm{Z} / \mathrm{D}=3$, the heat transfer profile tends to the conventional bell shape.

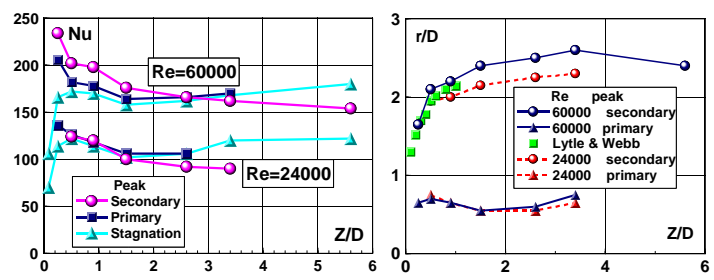

Fig. 5. Behaviour of heat transfer peaks for perpendicular SRN jet.

The VKI IR results shown in Fig. 6 reproduce the experiments that conducted Hollworth \& Gero (1985) with the microfoil - heat - flux - sensor technique. Although the IR results are somewhat above the data obtained Hollworth \& Gero, good agreement is found for the stagnation heat transfer that yields the following correlation:

$\mathrm{Nu}_{0}=\mathrm{C}_{\mathrm{O}} \mathrm{Re}^{0.65}$

Eq. (3) indicates that the flow in the stagnation zone is rather close to laminar regime, which is usually modelled by $\operatorname{Re}^{0.5}$.

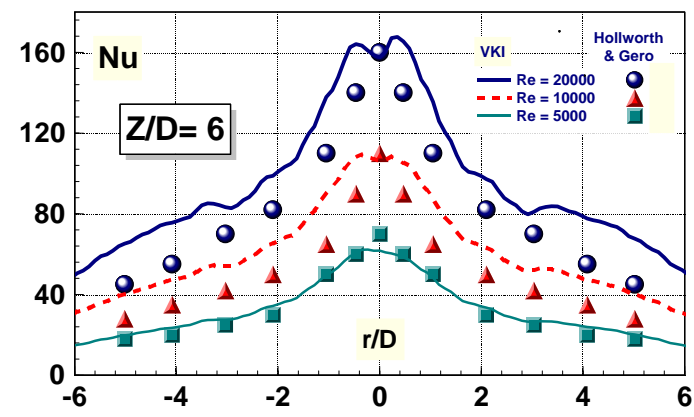

Fig. 6. Comparison between IR data and literature

An averaged stagnation Nusselt number $\mathrm{Nu}_{\mathrm{o}}$ defined as the mean coefficient between the stagnation value and the inner peak value when existing, is plotted versus the normalised standoff distance Z/D in Fig. 7. The IRthermography results compared well with data obtained with several other measurements techniques (Gardon \& Akfirat 1966; Hrycak 1983; Hollworth \& Gero 1985; Goldstein et al. 1986; Baughn \& Shimizu 1989; Gau \& Chung 1991). Most of the data confirm that the maximum of the stagnation heat- transfer rate is obtained when the normalised standoff distance has a value ranged between 6 and 8. This maximum, which depends also of the initial jet turbulence intensity (nozzle design) (Nakatogawa \& Nishiwaki 1970) occurs when the axial increase of turbulence in the jet due to air entrainment (mixing- induced turbulence), does not compensate for the fall in the jet velocity. In other words, that corresponds more or less to the end of the potential core and the arrival of turbulence from the shear layer at the stagnation zone.

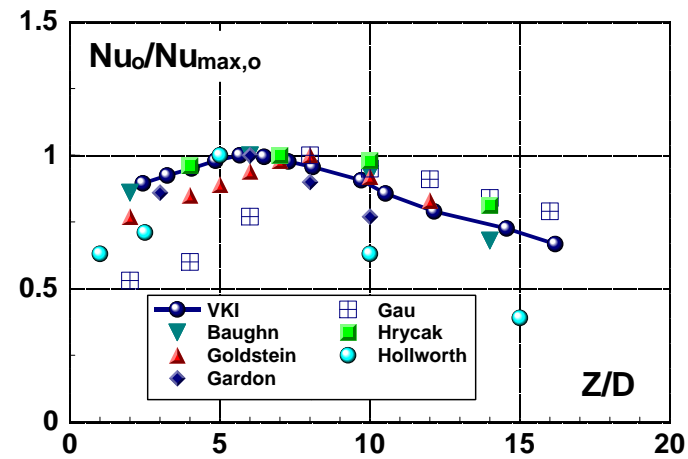

Fig. 7. Effect of the normalized standoff distance on the stagnation Nusselt number

\subsubsection{Isothermal Lobed Jet}

The design of the nozzle exit influences the jet behaviour and consequently may enhance or deteriorate the resulting convective heat transfer. In this purpose lobed nozzles have received also peculiar attention at the VKI (Herrero Martin and Buchlin 2010). Nozzles with the same hydraulic diameter but shaped with three (L3) and four (L4) lobes have been tested. Typical thermogrammes obtained with these nozzles are displayed in Fig. 8.
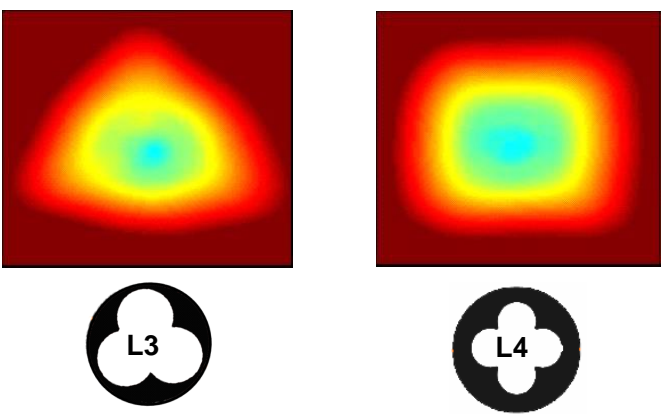

Fig. 8. Typical thermograms: $\mathrm{Re}=9000$ and $\mathrm{Z} / \mathrm{D}_{\mathrm{h}}=1$

As illustrated in Fig. 9, it turns out that for Reynolds number higher than 10000 the effect of the exit silhouette affects noticeably the heat transfer distribution. In terms of enhancement, the nozzle L3 prevails over the L4 nozzle, which yields similar performance than the round nozzle.
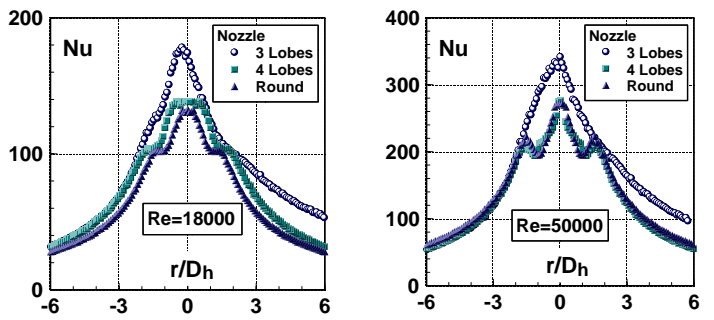

Fig. 9. Nusselt number distribution for lobed ad round nozzles: $\mathrm{Z} / \mathrm{Dh}=1.3$.

\subsubsection{Isothermal Tilted Jet}

In many applications, the shape of the target or the constraints on the nozzle positioning may lead to the formation of an oblique jet (Kamoi \& Tanaka 1972; 
Sparrow \& Lowell 1980). The jet impacts the target with a tilting angle. This situation has been studied in relation with jet/flap interaction (Foss \& Kleis 1972, 1973) and for confined liquid jet (Smirnov et al. 1961). Such a situation is also encountered when the impinging jet emerges in a cross flow which may be caused by the spent air in the case of arrays of nozzles. (Metzger \& Korstad 1970; Bouchez \& Goldstein 1975; Metzger et al. 1979; Goldstein \& Behbahani 1982; Florschluetz et al. 1984; Obot \& Trabold 1987).

As the jet impinges the solid surface with an angle of attack $\theta$ smaller than $90^{\circ}$ (with respect to the horizontal direction) the thermal field at the impact is distorted and an unbalanced local heat transfer is observed on the uphill and downhill sides. The thermogrammes displayed in Fig. 10 illustrate this effect.

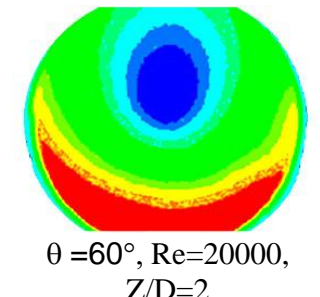

$\mathrm{Z} / \mathrm{D}=2$

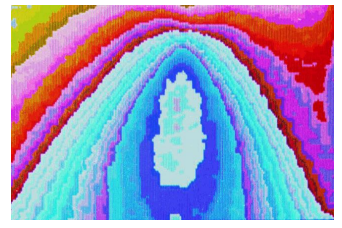

$\theta=15^{\circ}, \operatorname{Re}=65000$ $\mathrm{Z} / \mathrm{D}=7$
Fig. 10. Thermogrammes of impinging round jet

The tilting of the jet results in an enlargement the heat transfer area in the flow direction and a subsequent diminution of the heat transfer coefficient as shown in Fig. 11 where the reduced Nusselt number $\mathrm{Nu}^{*}$, defined as the ratio of $\mathrm{Nu}(\theta)$ to $\mathrm{Nu}\left(90^{\circ}\right)$ determined at the stagnation point for the same flow conditions, is plotted versus the angle of attack.
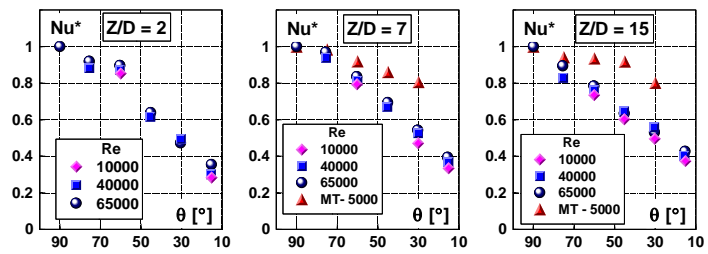

Fig. 11. Effect of the jet tilting angle on the stagnation Nusselt number

Notice that in agreement with published literature, the stagnation heat transfer point is displaced downstream and does not correspond to the geometrical impact of the jet (Bouchez \& Goldstein 1975; Sparrow \& Lowell 1980; Goldstein \& Behbahani 1982). This displacement increases as $\theta$ decreases. The modest scatter of the data leads to the conclusion that $\mathrm{Nu}^{*}$ is a weak function of $\operatorname{Re}$ in the range investigated $(10000 \leq \operatorname{Re} \leq 60000)$. Typically, as the angle of attack decreases of $50 \%$, the stagnation Nusselt number drops by $40 \%$ almost independently of the reduced standoff distance in the large range tested $(2 \leq Z / D \leq 15)$. This behaviour is much marked than the influence shown by the results of Sparrow \& Lowell (1980) when applying a mass transfer technique (MT=triangles in Fig. 11). The discrepancy may be explained by the lower value of the Reynolds number used in the mass transfer experiments.

\subsubsection{Non-Isothermal Jet}

In some impingement schemes, the jet is discharged in an environment at different temperature $T_{a}$. Due to momentum exchange, the jet entrains within it an amount of the surrounding air so that the effective fluidto- wall temperature difference is modified comparatively to the case of isothermal jet. Such an aerothermal process affects the performance of nonisothermal impinging jets. Literature reports several analytical and experimental studies devoted to this effect (Schauer \& Eustis 1963; Vlachapoulos \& Tomich 1971; Striegl \& Diller 1984; Flor- schuetz et al. 1984; Hollworth \& Wilson 1984a,b; Hollworth and Gero 1985).

To address such a rather complex problem, the simplest model of single, cooled or heated air jet, submerged in a quiescent air at room temperature and impinging normal to a constant- heat- flux flat plate is selected. The resulting data allow the identification of the mismatch temperature effect, $\Delta \mathrm{T}=\left|\mathrm{T}_{\mathrm{j}^{-}} \mathrm{T}_{\mathrm{a}}\right|$, on the convective heat transfer coefficient.

The entrainment process leads to a non uniform fluid temperature distribution at the plate surface. It can be readily determined by measuring the recovery or adiabatic temperature $T_{a w}$ measured on the plate for non- heating condition. The results are plotted in Fig. 12 in terms of the recovery factor $\Gamma$ defined as:

$$
\Gamma=\left(T_{a w}-T_{a}\right) /\left(T_{j}-T_{a}\right)
$$

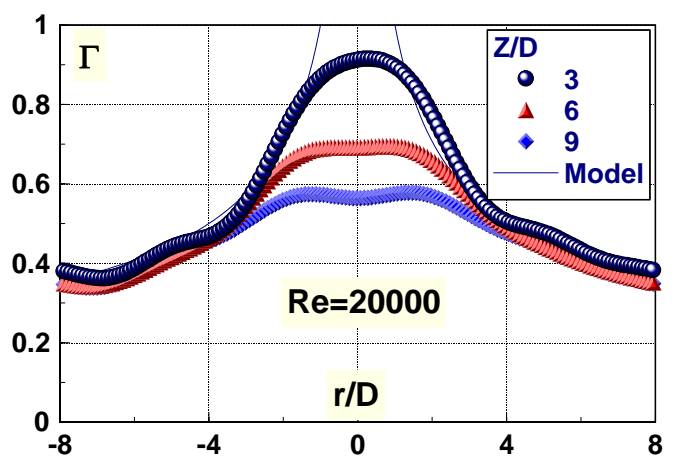

Fig. 12. Typical radial distribution of the recovery factor

For isothermal conditions, $\Gamma=1$. For non- isothermal jet, $\Gamma$ exhibits a radial variation. A maximum is located at the stagnation point where impinging flow preserves a temperature close to the plenum jet temperature $T_{j}$. The recovery factor decreases radially as the wall jet develops. That denotes the predominant presence of the entrained fresh air on the edges of the jet. Goldstein and Behbahani (1986) show that the recovery factor does not depend on the jet Reynolds number Re. On other hand, Hollworth and Wilson (1984) point out that above 3 , the normalised standoff distance has a weak influence on $\Gamma$ : subsequently, they suggest modelling the radial $\Gamma$-variation by:

$\Gamma=\mathrm{a}(\mathrm{r} / \mathrm{D})^{\mathrm{b}} \quad$ for $\Gamma \leq 1$

Eq. (5) is plotted in Fig. 12 for $a=1$ and $b=-0.5$ 
(exponent $\mathrm{b}$ different from the value of 0.95 proposed by the previous authors). Agreement is obtained in the wall jet region (typically for $\mathrm{r} / \mathrm{D}>2$ ).

To include the thermal entrainment effect in the heat transfer correlation, the recovery temperature $\mathrm{T}_{\mathrm{aw}}$ is taken as reference instead of $T_{j}$ in the definition of the convective coefficient (Eq. (1)). The Nu-definition becomes:

$$
\mathrm{Nu}^{\prime}=\frac{\mathrm{q}_{\mathrm{cv}}}{\mathrm{T}_{\mathrm{w}}-\mathrm{T}_{\mathrm{aw}}} \cdot \frac{\mathrm{D}}{\mathrm{k}_{\mathrm{a}}}
$$

Figure 13a proves the consistency of Eq. (4) since the stagnation Nusselt number $\mathrm{Nu}_{\mathrm{o}}$ ' remains fairly independent on the stagnation recovery factor $\Gamma_{0}$. The data scatter observed in Fig. 13a reflects the implicit effect of the standoff distance, which is clearly pointed out in Fig. 13b.

Whatever the sign of the mismatch temperature, the adiabatic temperature allows the account of the nonisothermicity of the jet. Moreover, Fig. 13b reveals also that significant discrepancy may appear between the Nusselt number values according to the temperature reference chosen.

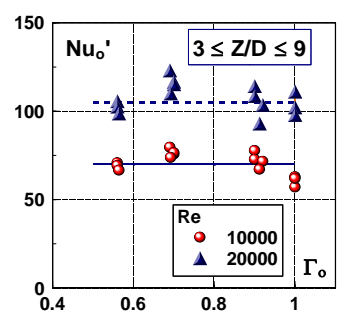

(a)

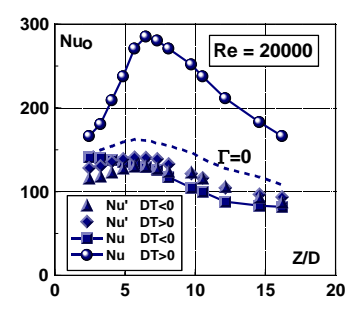

(b)
Fig. 13. Stagnation Nusselt number based on the adiabatic temperature

\subsubsection{Slot Jet on Concave Surface}

Jet impingement on a concave surface may lead to oscillating flow. The resulting convective heat transfer due to such a jet fluctuation may differ from the case of steady jet onto flat plate. Buchlin et al. (2008) have studied this flow situation; they investigated the behaviour of a planar jet impacting the internal apex of a V- shaped corner. Cheng- Kuang Lin et al. (1993) and Gwo- Bin Lee (2002) have proved that such geometry induces readily a periodic flapping motion of impinging slot jet.

Hot wire tests have been dedicated to the determination of the flapping frequency, $\mathrm{f}$, of the jet. FFT data processing of the output signal shows that the Strouhal number $\mathrm{Sr}=\mathrm{f} . \mathrm{Z} / \mathrm{U}$ is constant in the range of the Reynolds number tested, as depicted in Fig. 14.

The flapping behaviour of the jet produces a change in time of the convective heat transfer as observed in Fig. 15. Such results are proving that IR thermography technique is efficiently able to capture the trace of the sweeping jet and indicate that the local heat flux can vary by more than $20 \%$.

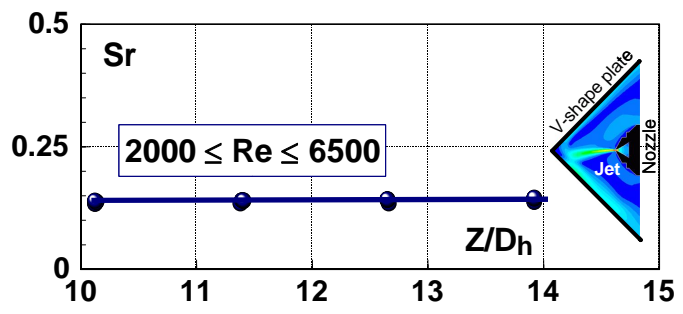

Fig. 14. Flapping Stroual number

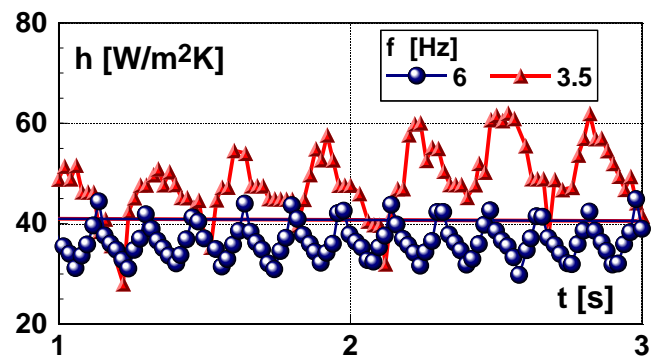

Fig. 15. Time variation of local heat transfer.

Figure 16 compares heat transfer data for V-shaped and flat plates obtained for same Reynolds number and apex standoff distance. The time average Nusselt number is plotted versus the transversal normalized distance. One observes that the jet flapping yields higher heat exchange performance mainly due to the periodic flow behaviour and reduction of the effective standoff distance when the jet is sweeping periodically.

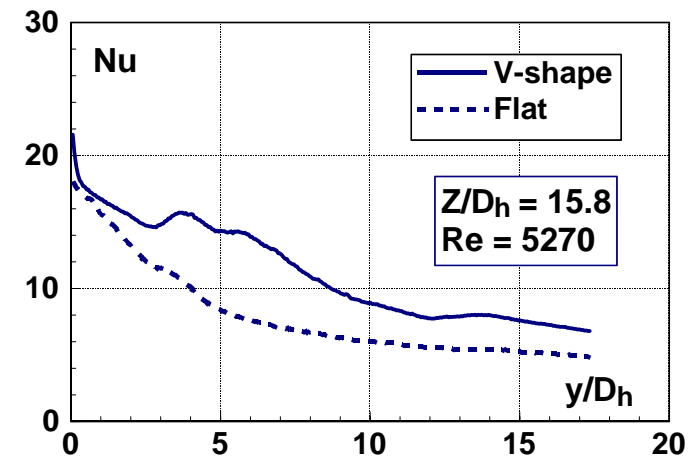

Fig. 16. V- shape - flat plate comparison

\subsection{Multiple Jet Systems}

Cooling devices based on impinging jets involve mainly arrangements of circular or plane jets.

ASN schemes are often used in paper drying, glass manufacturing and fast cooling of metal strip (Buchlin \& Dubois 1992; Buchlin at al. 2002b).

ARN schemes are frequently encountered in the internal cooling of high- performance gas turbine engines, in particular for gas combustor and both stator vanes and blades (Hollworth \& Berry 1978; Behbahani \& Goldstein 1983; Florschuetz et al. 1984; Florschuetz \& Su 1987; Al Dabagh et al. 1990; and Seol \& Goldstein 1991). They are also extensively applied to strip cooling (Buchlin et al. 2004) and thermal deicing systems of airplanes (Buchlin et al. 1994; Planquart et al. 2005). 


\subsubsection{ASN Schemes}

The study of ASN scheme involves a new design parameter, which is the nozzle- to- nozzle spacing, W, normalised by the hydraulic diameter $D_{h}$. The ASN design is first investigated by testing a 3- jet array. Such a simple configuration features the main phenomena that occur in multiple slot systems.

Experimental findings for $R e=11000$ and $W / D_{h}=10$ are presented in Fig. 17, where the Nusselt number distribution along the mid plane of the target, is plotted. The non- symmetry of the Nu- distribution with respect to the axis of the central jet, highlights the jet- to- jet interference as reported by Gardon \& Akfirat (1966), Hollworth \& Berry (1978), and Goldstein \& Timmers (1982).

At small normalised discharge distance equal to 8 , jetto- jet interaction occurs before impingement and heat transfer peaks are no longer equal. Such a jet layout is not stable, indeed: small difference in air supply may provoke unbalanced entrainment and subsequent destabilization. This is reflected by the deflection of the outer left jet, which triggers a drop of the heat transfer coefficient similarly to oblique impingement.

At higher standoff distance, $\mathrm{Z} / \mathrm{D}_{\mathrm{h}}=20$, and same Reynolds number, smoke flow visualization performed with laser- sheet technique, discloses the existence of large oscillations of the central jet. This jet flapping is characterized by a Strouhal number based on standoff distance, equal to 0.013 ; this value is very close to that obtained previously with the V- shape plate (\$3.1.4). In the present case the jet sweeping smoothes out the presence of the central stagnation heat transfer peak as shown in Fig. 17.

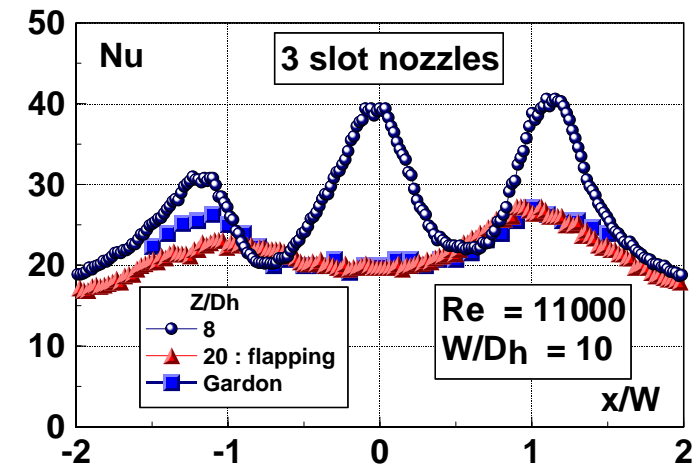

Fig. 17. Nu- profile for $A S N$ : effect of $Z / D_{h}$

Figure 18 reports an attempt to reproduce these experiments by CFD simulation, which is performed with Fluent code using a k- $\varepsilon$ turbulent model based on the Renormalization- group theory (Smith 1991). Good agreement is reached for the smaller standoff distance. As expected, the numerical computation does not capture the case of flapping condition although the predicted heat transfer peak values of the external jets do not differ drastically from the experimental data. From this experimental- CFD comparison, one can conclude that the central oscillating jet has not a so strong influence on the heat transfer in the stagnation zone of the two other neighbouring jets.
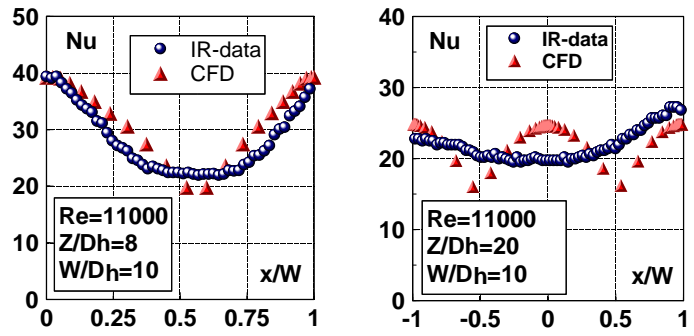

Fig 18. Experiment- CFD comparison: 3 slot nozzles

To get rid of end effect, the experiments are repeated with an array of 8 slot nozzles. Good repeatability of the heat transfer distribution is noticed in the central zone of the array. For design purpose, it is more convenient to express the heat transfer correlation in terms of an average dimensionless convective heat transfer coefficient defined as follows:

$\overline{\mathrm{Nu}}=\frac{\mathrm{D}_{\mathrm{h}}}{\mathrm{k}_{\mathrm{a}} \mathrm{W}} \int_{-\mathrm{W} / 2}^{\mathrm{W} / 2} \mathrm{~h}(\mathrm{x}) \mathrm{dx}$

The results are plotted in Fig. 19, where the IR- data are compared to predictions obtained with the correlation derived by Martin (1977) from mass transfer data, and CFD simulations achieved with Fluent code. Rather good agreement is noticed.

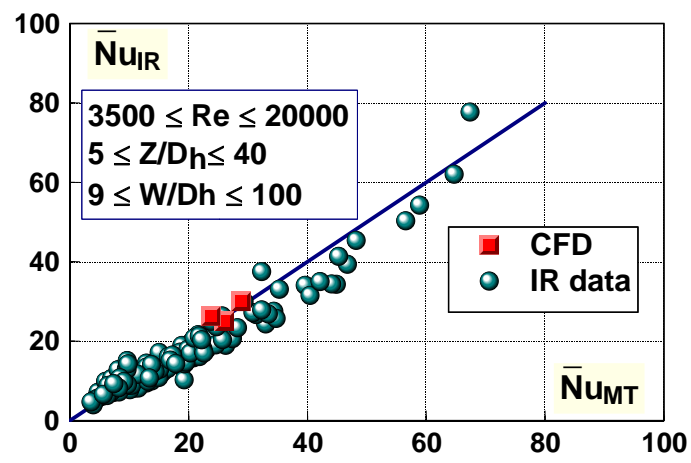

Fig. 19. Experiment- CFD comparison: ASN scheme

To assess the suitability of the ASN- correlation proposed in Fig. 18 to industrial situation, temperature measurements have been performed on an industrial galvanization line. Mean temperature of moving metallic strip has been measured with contact thermocouples at the inlet and outlet of a cooling system based on multiple slot jets. Simple lump capacity model is used to retrieve the values of the heat transfer coefficient from temperature measurements.

The good agreement depicted in Fig. 20 between the ASN- correlation and industrial data, confirm its applicability even for the high jet Reynolds number practised in the present galvanisation line. ASN experiments have also been conducted on a model reproducing at scale $1 / 3$ a industrial fast cooling plenum designed for continuous annealing or galvanizing lines. The schematic proposed in Fig. 20 shows that the plenum is composed of perpendicular $\left(90^{\circ}\right)$ and tilted $\left(60^{\circ}\right)$ slot nozzles with given emergence length, E. The normalised nozzle spacing may vary in the range 
$6 \leq \mathrm{W} / \mathrm{D}_{\mathrm{h}} \leq 18$; the normalised nozzle emergence length, $\mathrm{E} / \mathrm{D}_{\mathrm{h}}$, from 5 to 17 and the normalised standoff distance $\mathrm{Z} / \mathrm{D}_{\mathrm{h}}$ from 3 to 10 . The maximum Reynolds number can reach 100000 .

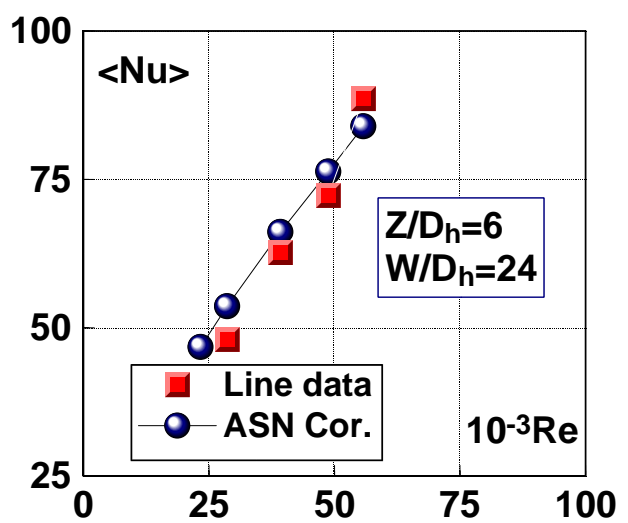

Fig. 20. Applicability of the ASN - correlation to galvanisation line

Figure 21 provides also a restored IR thermogramme corresponding to a typical slots arrangement. It is a faithful representation of the impinging flow. The lowest temperatures are found at the impingement of $90^{\circ}$ jet. The cooling rate decreases as the jet angle decreases. The very low spanwise distortion of the isotherm contours denotes the quasi two- dimensional character of the impinging flow for this specific configuration.

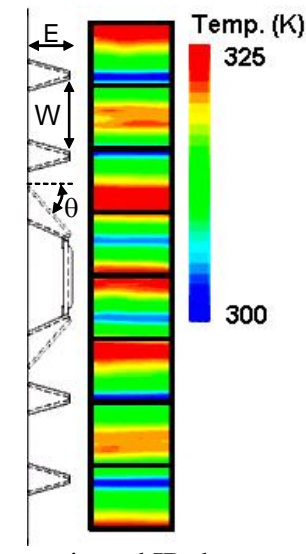

Fig. 21. Schematic and IR thermogramme of ASN plenum

However, 3D numerical simulations of such a situation has been performed with the code FLUENT. The mesh grid is composed of hexahedral elements leading to 300000 cells. Figure 22 displays the complete surface mesh of the computational domain. Standard k- $\varepsilon$ turbulence model with wall functions is used for the computation. Second order upwind discretisation scheme is used for all the equations solved in steady state. The standard Simple algorithm is adopted for the pressure- velocity coupling. The boundary conditions are imposed based on the experimental conditions (temperature and velocity of the impinging jets, temperature of the ambient air, heat flux imposed on the heated plate).

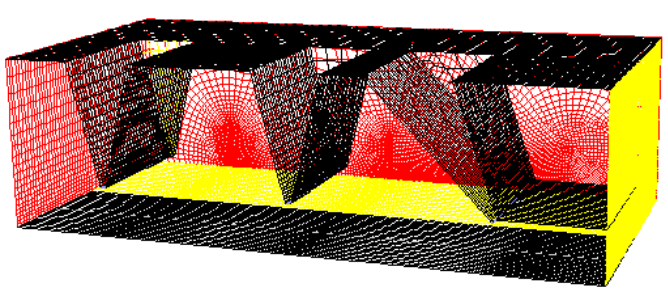

Fig. 22. Surface grid of the of ASN plenum simulation

Figure 23 exemplifies the comparison between IR measurements and CFD simulation. The Nusselt number distribution along the centre line of the plate is plotted versus the normalized axial distance. On the whole, one can spot good agreement considering such a complex flow topology. Maximum predicted $\mathrm{Nu}-$ values are within $10 \%$ of the experimental data. Yet minimum $\mathrm{CFD} \mathrm{Nu}$ - values occurring between the jets are smaller than the experimental data. This discrepancy results from the weak capability of the present steady state CFD modelling to capture the position of the separation point and the associated drop of heat transfer rate.

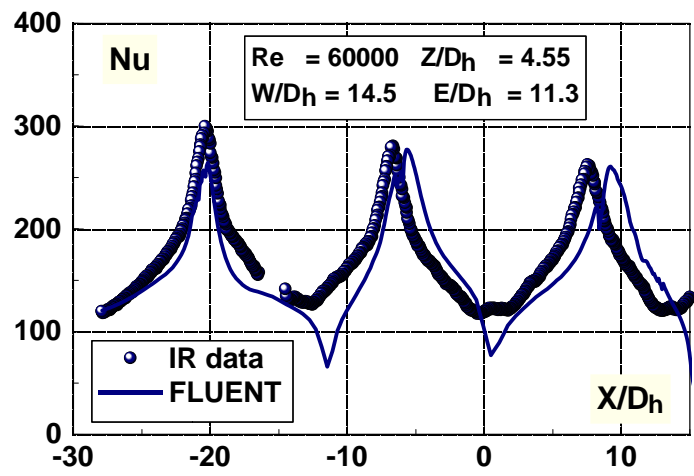

Fig. 23. Experimental - numerical comparison for ASN plenum

\subsubsection{ARN Schemes}

Typical distribution of the dimensionless heat transfer coefficient in the case of three collinear round jets produced by nozzles separated by 4 orifice diameters is displayed in Fig. 24. A turbulent jet Reynolds number equal to 22000 characterizes the flow conditions. The $\mathrm{Nu}$ - profile plotted along the central impingement line is limited to the region including the inner and one outer jet. Figure 24 affords additional interesting information compared to Fig. 17.

At low nozzle- to- plate distance $(\mathrm{Z} / \mathrm{D}=2)$, the main stagnation region of the jets exhibits a heat transfer minimum, however less pronounced than in the case of single jet, indicating that the jet- to- jet interaction enhances the mixing-induced turbulence that penetrates further in the core of the jet. Midway between the impingement points, a secondary heat transfer peak arises. In their study, Gardon \& Akfirat (1966) and Goldstein \& Timmers (1982) make the same observation. Additional static pressure measurements on the plate testify that the secondary $\mathrm{Nu}$ maximum is correlated to a secondary pressure peak and provide physical explanation. As the wall jets approach one 
another, the pressure gradient increases provoking a thickening the boundary layer: hence, a flow separation should follow leading to the formation of a complex three- dimensional vortical flow topology. Following Didden \& Ho (1985), one anticipates that such a boundary layer separation evolves into the formation of a large primary vortex associated with an intense secondary vortex of opposite rotation that downwashes the wall creating a high heat transfer rate.

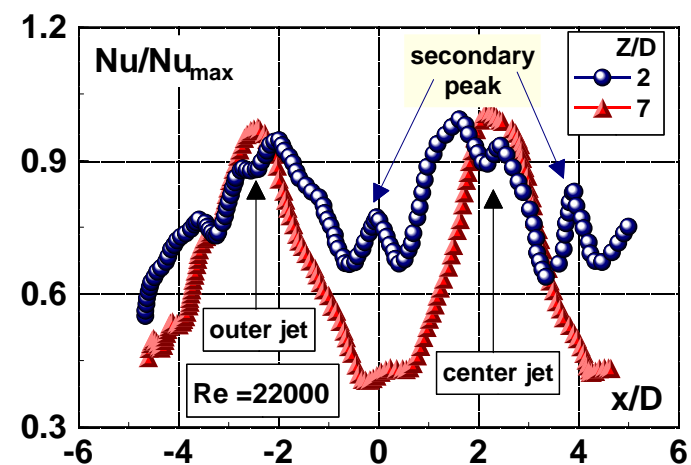

Fig. 24. Nu distribution for collinear round jets.

Figure 25 displays typical mappings of the convective heat transfer coefficient in the case of staggered and non- staggered round jet configuration.

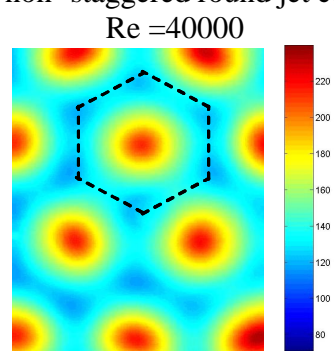

(a) Staggered

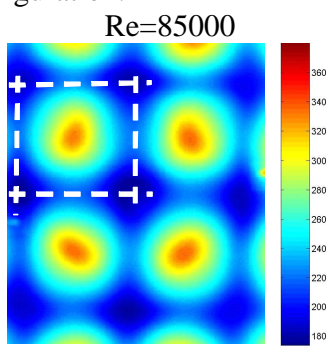

(b) Non staggered
Fig. 25. IR thermogrammes in ARN.

An average Nusselt number is calculated on the cell area defined by dashed contour specified in Fig. 25. A relevant way to compare the present IR findings to published data is to reformulate the results in terms of dimensionless groups introduced by Martin (1977). The averaged Nusselt number is normalised by the fluid Prandt number, Pr, and geometrical functions, which account for the effect of Z/D and W/D as follows:

$\overline{\mathrm{Nu}}^{*}=\frac{<\mathrm{Nu}>}{\mathrm{Pr}^{0.42} \mathrm{G}^{*} \mathrm{~K}} \square \mathrm{Re}^{2 / 3}$

where

$$
\begin{aligned}
& G=\left\{\begin{array}{ccc}
1 & \text { if } & F<1 \\
F^{-0.3} & \text { if } & F>1
\end{array} \quad \text { with } F=\frac{Z / D}{0.6 / \sqrt{f}}\right. \text { and } \\
& \text { and } f=\frac{\frac{\pi}{4} D^{2}}{\text { Averaging Area }} \\
& \left.K=2 \sqrt{f} \cdot \frac{1-2.2 \cdot \sqrt{f}}{1+0.2 \cdot(Z / D-6) \cdot \sqrt{f}}\right)
\end{aligned}
$$

The correlation (Eq. 8) is announced to be valid for $2 \leq \mathrm{Z} / \mathrm{D} \leq 12,2000 \leq \mathrm{Re} \leq 100000$ and $0.004 \leq \mathrm{f} \leq 0.04$. The IR data for square and triangular patterns, which satisfy as close as possible the conditions of application of the correlation (8) are plotted in Fig. 26. They are compared to different published experimental data. Figure 26 points out that the IR data could be $15 \%$ to $30 \%$ lower that the prediction obtained by the correlation (8) plotted as continuous line. Although the trend $\mathrm{Re}^{2 / 3}$ is well reproduced, the spreading of the data at constant Re indicates that Eq. (8) does not take into account satisfactorily the effect of the geometrical parameters such as Z/D and W/D. Additionally the data indicate that arranging the round nozzles in a square or triangular pattern does not yield any difference in the final mean heat transfer coefficient.

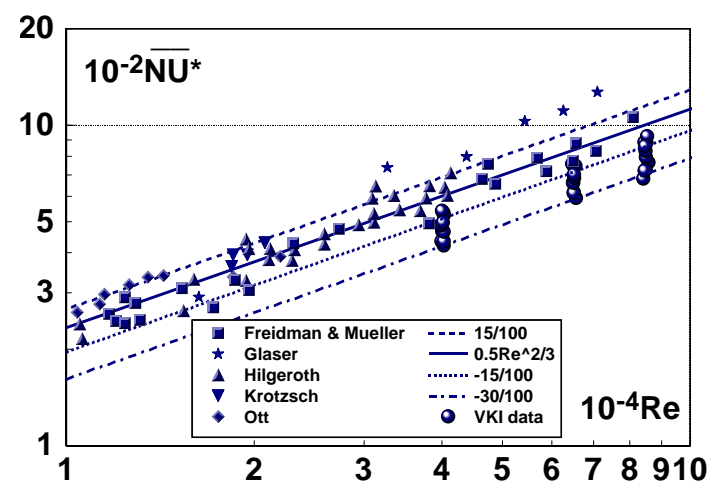

Fig. 26. Heat transfer correlation for ARN systems.

Recent designs of deicing or antiicing devices of wing and tail surfaces of airplanes are based on the aerothermal effect of ARN arrangements. A perforated duct called "piccolo " supply hot round as sketched in Fig. 27. Such a configuration, which emphasises the impingement of multiple jets on concave target, is also encountered in the cooling of turbine blades (Metzger et al. 1969). The hot air issuing from the holes and flowing on the inner surfaces of the skin prevents the ice formation on the leading edge of the wing when adverse flight conditions are experienced.

The operating window of thermal antiicing devices may be rendered rather narrow due to the limited amount of hot air delivered by the engines. Therefore, efficient design requires identifying the key parameters that control the convective heat transfer coefficient. Its distribution on the concave surface that constitutes the leading edge of an airfoil can be obtained by use of the quantitative IR thermography.

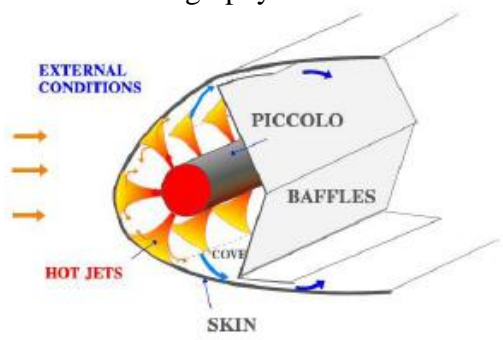

Fig. 27. Principle of thermal deicing

A typical mapping of the convective heat transfer coefficient for an arrangement of four rows of jets is shown in Fig. 28. It results from IR camera scanning from the intrados to the extrados of the leading edge. The abscissa $\mathrm{x}$, and ordinate $\mathrm{y}$, are normalised by the 
model length 1 and the chordwise length $\mathrm{L}$, respectively. The confinement effect of the two central rows is depicted by the highest h-values obtained in this zone. A sharp decrease of thermal exchange is also observed on the far intrados and extrados where the multiple jet effect becomes weak.

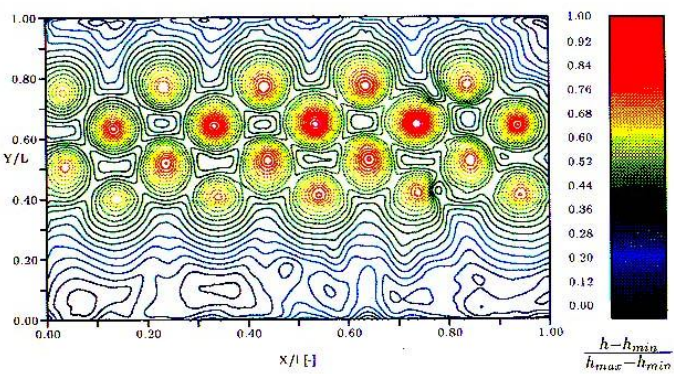

Fig. 28. Heat transfer map in antiicing system

As usual, engineering consideration demands to calculate a mean heat transfer coefficient. Here, the average area is the cell of the jet array. Dimensional analysis recommends plotting the dimensionless group $<N u>/ \operatorname{Re}^{\mathrm{m}} P r^{\mathrm{n}}$ versus a geometrical factor $G_{o}$ defined as following:

$$
\mathrm{Go}_{\mathrm{a}} \mathrm{n}_{\mathrm{j}}^{\mathrm{a}}\left[\frac{\mathrm{S}_{\mathrm{c}}}{\mathrm{D}}\right]^{-\mathrm{a}}\left[\frac{\mathrm{S}_{\mathrm{p}}}{\mathrm{D}}\right]^{-\mathrm{b}}\left[\frac{\mathrm{Z}}{\mathrm{D}}\right]^{-\mathrm{C}}
$$

where $n_{\mathrm{j}}$ is the number of jets in the cell. Figure 29 demonstrates the pertinence of the present Piccolo correlation. Since the Prandtl number does not vary substantially in the IR experiments, the exponent $n$ is set equal to 0.4 to be consistent with literature. The Reynolds exponent $m$ is found equal to 0.8 in good agreement with data of Hollworth \& Berry (1978), Behbahani \& Goldstein (1983) and Florschuetz et al. (1984). However, it differs from the value of 0.7 obtained by Jusionis (1970) and from the data of Meola et al. (1994) who reach a surprising high value of 1.39 . The curve- fit shown in Fig. 29 yield $a=0.4, b=0.9$ and $c=0.1$.

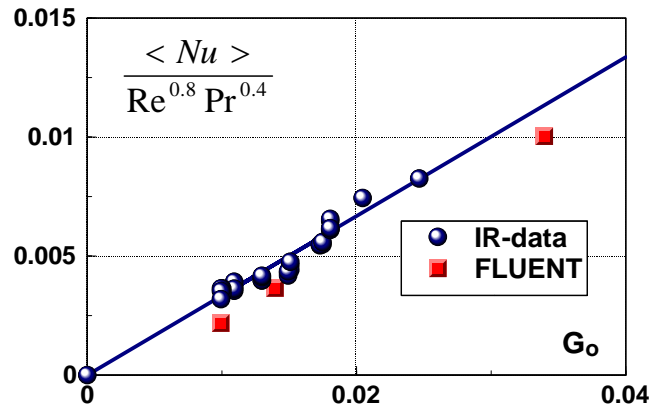

Fig. 29. Piccolo Heat transfer correlation

In the range of the geometrical parameters investigated, the normalised piccolo- to- skin distance has a small influence on the convective thermal exchange. Such a result fits the conclusion drawn by Kercher \& Tabakoff (1970), Hollworth \& Berry (1978) and Meola et al. (1994) while the Jusionsis's correlation predicts a more pronounced effect since $c=0.4$.

The dominant parameter is the reduced spanwise jet spacing: as $S_{\mathrm{p}} / d$ decreases the dead zone between the jet impingement shrinks and the average heat transfer rises.
The results of 3D numerical simulation performed with Fluent code are also plotted in Fig. 29. They show that CFD simulation approaches well the Piccolo correlation.

\section{Conclusions}

Convective heat transfer at the impact of impinging gas jets on a solid surface is presented. Single and multiple jet systems based on round or slot nozzles are considered. The heat transfer data are obtained from the application of infrared thermography. Some PIV, hot wire and pressure measurements support the physical flow interpretation. Additionally numerical simulation is conducted with the FLUENT code. The flow and geometrical parameters as well as the environmental conditions at which the jet emerges are emphasised.

The impingement zone is generally characterised by a complex vortical flow topology. At low normalised nozzle- to- wall distance, the heat transfer distribution of single isothermal vertical jet may exhibit two maxima controlled by flow acceleration and transition to turbulence. As the discharge distance increases, the mixing- induced turbulence leads to a more conventional bell- shape profile. Stagnation heat transfer coefficient reaches a maximum for standoff distance ranging between 6 to 8 orifice diameters. Heat transfer coefficient increases with the jet Reynolds number with an exponent- value ranging from 0.5 to 0.8 .

The design of the nozzle exit may influence the jet development and consequently may affect the convective heat transfer. The tilting of the jet provokes a distortion of the heat transfer distribution and a decrease of the stagnation value. Jet impingement on a concave surface may lead to oscillating flow characterised by a constant flapping Strouhal number; the resulting jet sweeping enhances heat exchange.

Heat transfer performance of a non- isothermal jet is affected by the thermal entrainment process and reliable heat transfer correlation has to be based on the adiabatic wall temperature. Such an entrainment phenomenon may become a key parameter in single jet confinement or multiple jet arrangements.

In nozzle array systems the standoff distance and the nozzle- to- nozzle spacing control the jet- to- jet interaction. Jet flapping has also been observed in ASN schemes; in this case the jet fluttering brings about a smoothing of the heat transfer distribution. In ARN schemes and at low standoff distance, a secondary heat transfer peak may arise midway two jets due to their strong interaction. The ASN and ARN layouts are illustrated through industrial and aeronautical applications such as the fast cooling of moving metallic strips and the thermal anticing of airplanes. IRthermography provides reliable design correlations which compare well to literature and CFD computations.

\section{REFERENCES}

Al Dabagh, A.M., G.E. Andrews, R.A.A. Abdul Husain, C.I. Husain, A. Nazari and J. Wu (1990). 
Impingement by effusion cooling: the influence of the number of impingement holes and pressure loss on the heat transfer coefficient. Journal of Turbomachinery, Transaction of Asme 112/467, 467- 476 .

Balageas, D.L. (1993). Fundamentals of I.R. Thermography. V.K.I. Lectures Series, 19-23.

Baughn, J.W. and S. Shimizu (1989). Heat transfer measurement from a surface with uniform heat flux and an impinging jet. ASME Journal of Heat Transfer 111, 1096- 1098.

Behbahani, A.I. and R.J. Goldstein (1983). Local heat transfer to staggered arrays of impinging circular air jets. Journal of Engineering for Power 105, 354- 360 .

Bouchez J.P. and R.J. Goldstein (1975). Impingement cooling from a circular jet in a cross flow. JHMT 18(6), 719-730

Buchlin, J.M. (1986a, May). Digital image processing technique applied to fluid dynamic problems. AGARD PEP 67th Symp. on Advanced Instrumentation for Aero Engine Components, Philadelphia, USA.

Buchlin, J.M. (1986b, June). Thermography application to heat transfer of impinging jets in "Flow visualization and digital image processing". Lecture - Series 1986-09, von Karman Institute for Fluid Dynamics, Rhode Saint Genèse, Belgium, 13-22.

Buchlin, J.M. and T. Arts (1991, October). Mesure de températures de surface par cristaux liquides et thermographie infrarouge. VKI- Preprint 1991-31, 'Journées d'Etudes et Exposition; Développements récents en transfert de chaleur. Applications et produits nouveaux.' Société Belge des Mécaniciens, Bruxelles.

Buchlin, J.M. and M. Dubois (1992). Heat transfer of impinging multijet system. An application of the quantitative thermography. In: Quantitative Infrared Thermography QIRT 92 (Balageas D, Busse G, Carlomagno GM, eds), 117- 120, Eds. Européennes Thermique et Industrie.

Buchlin, J.M. (1993). Heat transfer behind a rectangular cylinder in a boundary layer. In: Proceedings of the Workshop Advanced Infrared Technology and Applications, Atti Fond. G. Ronchi, Thermography 49(1), 305- 315.

Buchlin, J.M., H. Pretrel, P. Planquart, H. Langer and F. Thiry (1994). Infrared thermography study of a thermal anti- icing system. In: Quantitative Infrared Thermography QIRT 94 (Balageas D, Busse G, Carlomagno GM, eds), 133- 138, Eds. Européennes Thermique et Industrie.

Buchlin, J.M. and M. Peelman (1996, May). Natural convection along a vertical slender cylinder.
Eurotherm Proceedings: Second European Thermal Sciences, Roma, Italy.

Buchlin, J.M. and R. Tasse R. (1996). Convective heat transfer along slender cylinders. In: Quantitative Infrared Thermography QIRT 96 (Balageas D, Busse G, Carlomagno GM, eds), 129-134, Edizioni ETS.

Buchlin, J.M. and M. Meyers (1996). Infrared thermography study of a confined impinging circular jet. In: Quantitative Infrared Thermography QIRT 96 (Balageas D, Busse G, Carlomagno GM, eds), 159- 164, Edizioni ETS.

Buchlin, J.M. and M. Laperches (1998). Detailed investigation of aerothermal behaviour of confined impinging jet. In: Quantitative Infrared Thermography QIRT 98 (Balageas D, Busse G, Carlomagno GM, eds), 258- 264, Eds. Lodart S.A.

Buchlin, J.M. (2002a). Convective heat transfer in a channel with perforated ribs $=$ Transfert de chaleur par convection dans un canal muni de pontets perforés. International Journal of Thermal Sciences 41(4), 332- 340.

Buchlin, J.M., J.B. Gouriet, P.H. Planquart, J. Van Beeck and M. Renard (2002b, July). Experimental and numerical study of a convective heat transfer in an array of slot jets. ASME Flows in Manufacturing Processes, Montréal, Québec, Canada.

Buchlin, J.M., J. Brossard and J.B. Gouriet (2004, July). Infrared Thermography Study of Heat Transfer in an Array of Round Jets. $7^{\text {th }}$ International Conference of Quantitative Infrared Thermography, QIRT2004, von Karman Institute, Rhode- SaintGenèse, Belgium.

Buchlin, J.M., I.A. Horvath, R. Herrero and Ph. Planquart (2008, July). Thermal Study of Flapping Jet by Infrared Thermography. $9^{\text {th }}$ International Conference on Quantitative Infrared Thermography, QIRT 2008, Krakow, Poland.

Buchlin, J.M. (2010). Convective Heat Transfer and Infrared Thermography (IRTh). Journal of Applied Fluid Mechanics 3(1), 55- 62.

Carlomagno, G.M. (1993, April). Infrared Thermography. V.K.I. Lectures Series 19- 23.

Carlomagno, G.M. (1997). Thermo- fluid- dynamic applications of quantitative infrared thermography. Journal of flow visualization and image processing 14, 261- 280.

Carlomagno, G.M., G. Cardone, C. Meola and T. Astarita (1998). Infrared thermography as a tool for thermal surface flow visualization. Journal of Visualization 1(1), 37-50.

Cheng-Kuang, L., F.B. Hsiao and S.S. Sheu (1993). Flapping motion of a Planar Jet Impinging on a V- 
shaped Plate. Journal of Aircraft 30(3), 320-325.

De Luca, L., G. Cardone and G.M. Carlomagno (1992). Fluid dynamics applications of IR imaging systems. In: Quantitative Infrared Thermography QIRT 92 (Balageas D, Busse G, Carlomagno GM, eds), 98-104, Eds. Européennes Thermique et Industrie.

Den Ouden, C. and C.J. Hoogendoorn (1974). Local convective- heat- transfer coefficients for jet impinging on a flat plate, Experiments using aq liquid- crystal techniques. Heat Transfer 1974, Proceedings of the $5^{\text {th }}$ International Heat Transfer Conference 5, Tokyo, paper MA2.5, 293- 297.

Didden, N. and C.M. Ho (1985). Unsteady separation in boundary layer produced by an impinging jet. Journal of Fluid Mechanics 160, 235-256.

Florschuetz, L.W., D.E. Metzger and C.C. Su (1984). Heat transfer characteristics for jet array impingement with initial cross flow. ASME Journal of Heat Transfer 106, 34-41.

Florschuetz, L.W. and C.C. Su (1987). Effect of crossflow temperature on heat transfer within an array of impinging jets. ASME Journal of Heat Transfer 109, 74-81.

Foss J.F. and Kleis S.J.- The oblique impingement of an axisymmetric jet. NASA CR 134961 - N7616375, Vol. 1 \&2, December 1972.

Foss, J.F. and S.J. Kleis (1973). Preliminary result for a large angle oblique jet impingement and flow and for the effect of initial conditions on the near field of an axisymmetric jet. NASA CR 121257 - N7328177.

Gardon, R. and J.C. Akfirat (1965). The role of turbulence in determining the heat transfer characteristic of impinging jets. JHMT 8(9), 12611272 .

Gardon, R. and J.C. Akfirat (1966). Heat transfer characteristics of impinging two- dimensional air jets. ASME Journal of Heat Transfer 88, 101-108.

Gartenberg, E. (1992). Retrospective on aerodynamics research with infrared imaging. In: Quantitative Infrared Thermography QIRT 92 (Balageas D, Busse G, Carlomagno GM, eds), 63-85, Européennes Thermique et Industrie.

Gau, C. and C.M. Chung (1991). Surface curvature effect on slot- air- jet impingement cooling flow and heat transfer process. ASME Journal of Heat Transfer 113, 858-864.

Goldstein, R.J. and A.I. Behbahani (1982). Impingement of a circular jet with an without cross flow. JHMT 25(9), 1377-1382.

Goldstein, R.J. and J.F. Timmers (1982). Visualisation of heat transfer from arrays of impinging jets.
JHMT 25(12), 1857- 1868.

Goldstein, R.J., A.I. Behbahani and K. Kieger Heppelmann (1986). Streamwise distribution of the recovery factor and the local heat transfer coefficient to an impinging circular air jet. JHMT 29(8), 1227-1235.

Goldstein, R.J., K.A. Sobolik and W.S. Seol (1990). Effect of entrainment on the heat transfer to a heated circular air jet impinging on a flat surface. ASME Journal of Heat Transfer 112, 608-611.

Gwo-Bin, L., K. Tzu-Ying and W. Wan-Yu (2002). A novel micromachined flow sensor using periodic flapping motion of a planar jet impinging on a Vshaped plate. Experimental Thermal and Fluid Sciences 26, 435-444.

Hollworth, B.R. and R.D. Berry (1978). Heat transfer from arrays of impinging jets with large jet- to- jet spacing. ASME Journal of Heat Transfer 100, 352357.

Hollworth, B.R. and S.I. Wilson (1984). Entrainment effects on impingement heat transfer: Part I Measurements of heated jet velocity and temperature distributions and recovery temperatures on target surface. ASME Journal of Heat Transfer 106(4), 797-803.

Hollworth, B.R. and L.R. Gero (1985). Entrainment effects on impingement heat transfer: Part IILocal heat transfer measurements. ASME Journal of Heat Transfer 107, 910-915.

Hrycak, P. (1983). Heat transfer from round impinging jets to a flat plate. JHMT 26(12), 1857-1865.

Huang, G.C. (1963). Investigation of heat- transfer coefficients for air flow through round jets impinging normal to a heat transfer surface. $A S M E$ Journal of Heat Transfer 85(3), 237-245.

Jumbunathan, K., E. Lai, M.A. Moss and B.L. Button (1992). A review of heat transfer data for single circular jet impingement. Int. J. Heat and Fluid Flow, 13(2).

Jusionis, V.J. (1970). Heat transfer from impinging gas jets on an enclosed concave surface. Journal of Aircraft 7(1), 87-88.

Kamoi, A. and H. Tanaka (1972). Measurement of wall shear stress, wall pressure and fluctuations in the stagnation region produced by oblique jet impingement. Fluid Dynamic Measurement Conferences 1.

Kercher, D.M. and W. Tabakoff (1970). Heat transfer by a square array of round air jets impinging perpendicular to a flat surface including the effect of spent air. Journal of Engineering for Power, Transaction of ASME 92(1), 73-82.

Koopman, R.N. and E.M. Sparrow (1976). Local and 
average transfer coefficient due to an impinging row of jets. JHMT 19(6), 673-683.

Landreth, C.C. and R.J. Adrian (1990). Impingement of a low Reynolds number turbulent circular jet onto a flat plate at normal incidence. Experiments in Fluids 9, 74-84.

Lytle, D. and B.W. Webb (1991). Secondary heat transfer maxima for air jet impingement at low nozzle- to- plate spacings. In: Experimental heat transfer, Fluid Mechanics, and Thermodynamics, Edts Feffer J.F., Shah R.K. \& Ganic E.N., Elsevier.

Martin, H. (1977). Heat and Mass Transfer between impinging gas jets and solid surfaces. Adv. Heat Transfer 13, 1-60.

Meola, C., L. De Luca and G.M. Carlomagno (1994a). Thermal measurements in a single axisymmetric jet impinging normal to a flat plate. In: Quantitative Infrared Thermography QIRT 94 (Balageas D, Busse G, Carlomagno GM, eds), 180-185, Eds. Européennes Thermique et Industrie.

Meola, C., G.M. Carlomagno, E. Riegel and F. Salvato (1994b). Infrared thermography on testing an antiicing device. In: Quantitative Infrared Thermography QIRT 94 (Balageas D, Busse G, Carlomagno GM, eds), 186-191, Eds. Européennes Thermique et Industrie.

Meola, C., L. De Luca and G.M. Carlomagno (1995). Azimuthal instability in an impinging jet: adiabatic wall temperature distribution. Experiments in Fluids 18, 303-310.

Meola, C., L. De Luca and G.M. Carlomagno (1996). Influence of shear layer dynamics on impinging heat transfer. Experimental Thermal and Fluid Science 13, 29-37.

Metzger, D.E., T. Yamashita and C.W. Jenkins (1969). Impingement cooling of concave surfaces with lines of circular air jets. Journal of Engineering for Power, 149-158.

Metzger D.E. and Korstad R.J - Effect of cross flow on impingement heat transfer. Journal of Engineering for Power, pp 35- 41, January 1972.

Metzger, D.E., L.W. Florschuetz, D.I Takeuchi, R.D. Behee and R.A. Berry (1979). Heat transfer characteristics for in- line and staggered arrays of circular jets with cross flow of spent air. ASME Journal of Heat Transfer 101(3), 526-532.

Nakatogawa, T. and N. Nishiwaki (1970). Heat transfer of round turbulent jet impinging normally on flat plate. Heat Transfer 1970, Proceedings of the $4^{\text {th }}$ International Heat Transfer Conference, ParisVersailles, VOL II, Forced Convection Session paper FC5.2.

Obot, M.T. and T.A. Trabold (1987). Impingement heat transfer within arrays of circular jets: Part 1Effects of minimum, intermediate, and complete cross flow for small and large spacings. ASME Journal of Heat Transfer 109, 872-879.

Page, R.H., C. Ostowari, J. Seyed-Yagoobi and T.C. Gruber (1993). Measurement of impinging jet heat transfer utilizing infrared techniques. Experimental Heat Transfer, Fluid Mechanics and Thermodynamics, 726-732.

Planquart, Ph., G. Vanden Borre and J.M. Buchlin (2005). Experimental and Numerical Optimization of a Wing Leading Edge Hot Air Anti-Icing System. $43^{\text {th }}$ AIAA Aerospace and Sciences Meeting \& Exhibit, Reno.

Schauer, J.J. and R.H. Eustis (1963). The Flow Development and Heat Transfer Characteristics of Plane Turbulent Impinging Jets. Standford University, TR No. 3.

Seol, W.S. and R.J. Goldstein (1991). Heat transfer to a row of impinging circular jets including the effect of entrainment. JHMT 34(8), 2133-2147.

Smirnov, V.A., G.E. Verovochkin and P.M. Brdlick (1961). Heat transfer between a jet and a held plate normal to flow. JHMT 2(1/2), 1-7.

Smith, L.M. (1991). RNG and turbulence modelling. In: New approaches in the description and modelling of turbulence. VKI-Lecture-Series.

Sparrow, E.M. and B.J. Lovell (1980). Heat transfer characteristics of an obliquely impinging circular jet. ASME Journal of Heat Transfer 102(1), 64-70.

Striegel, S.A. and T.E. Diller (1984a). The effect of entrainment temperature on jet impingement heat transfer. ASME Journal of Heat Transfer 106, 27-33.

Striegel, S.A. and T.E. Diller (1984b). An analysis of the effect of entrainment temperature on jet impingement heat transfer. ASME Journal of Heat Transfer 106(4), 804-810.

Vallis, E.A, M.A. Patrick and A.A. Wragg (1978, August). Radial distribution of convective heat transfer coefficient between an axisymmetric turbulent jet and a flat plate held normal to the flow. $6^{\text {th }}$ International Heat Transfer Conference, Toronto. 